\title{
Accuracy and Pitfalls in the Assessment of Early Gastrointestinal Lesions
}

\author{
Tomica Milosavljevic ${ }^{a, b}$ Dusan Popovic ${ }^{a, b}$ Simon Zec ${ }^{b}$ Miodrag Krstic ${ }^{a, b}$ \\ Dragana Mijac ${ }^{\mathrm{a}, \mathrm{b}}$ \\ ${ }^{a}$ Clinic for Gastroenterology and Hepatology, Clinical Center of Serbia, Belgrade, Serbia; ${ }^{\text {b}}$ Faculty of Medicine, \\ University of Belgrade, Belgrade, Serbia
}

\author{
Keywords \\ Esophageal cancer · Gastric cancer - Colorectal cancer . \\ Endoscopy · Polyps
}

\begin{abstract}
Superficial neoplastic lesions of the digestive tract are usually asymptomatic, and often represent incidental findings on endoscopy. The Paris Classification was developed for the systematic evaluation of superficial lesions of the oesophagus, stomach and colon. The significance of this classification in clinical practice is that it allows the depth of invasion to be estimated. Chromoendoscopy is used to improve the visualization of gastrointestinal lesions. There are 2 types of chromoendoscopy: dye and virtual chromoendoscopy. In addition to chromoendoscopy, advanced endoscopy techniques have great importance in the detection of early gastrointestinal lesions. Although the depth of invasion can be estimated by endoscopy, the final decision regarding therapeutic approach is made on the basis of histopathological examination, as obtained by biopsy or endoscopic resection (ER). Polypectomy, endoscopic mucosal resection, and endoscopic submucosal dissection may be considered ER. For early gastrointestinal lesions with or without limited submucosal infiltration, ER can serve as therapy. In patients with
\end{abstract}

\section{KARGER}

() 2018 S. Karger AG, Basel

E-Mail karger@karger.com

www.karger.com/ddi neoplastic lesions localized deeper than the submucosa, or if the location of the lesion carries a high risk of perforation, a full-thickness resection can be performed. Guidelines for assessment and therapy of early oesophageal, gastric and colorectal lesions are currently available.

(c) 2018 S. Karger AG, Basel

\section{Classifications}

Superficial neoplastic lesions of the digestive tract are usually asymptomatic, often represent incidental findings on endoscopy and are defined as either superficial invasive or non-invasive [1]. The Paris Classification was developed for the systematic evaluation of superficial lesions in the oesophagus, stomach and colon [1]. Superficial carcinomas are defined as those lesions extending through the mucosa and submucosa of the digestive tract [1].

These lesions can be polypoid and non-polypoid. Polypoid lesions are those that protrude into the lumen of the digestive tube (Paris $0-\mathrm{I}$ ), can be pedunculated (0-Ip), sessile (0-Is) and semi-pedunculated (0-Isp) [1]. Nonpolypoid lesions include ulcerative (0-III) and flat lesions (0-II) [1]. Flat lesions, depending on the level of sur-

Prof. Tomica Milosavljevic, MD, PhD

Clinic for Gastroenterology and Hepatology, Clinical Center of Serbia Faculty of Medicine, University of Belgrade

Koste Todorovica 6, RS-11000 Belgrade (Serbia)

E-Mail tommilos@ hotmail.com 
Fig. 1. Paris and laterally spreading tumour classification $[1,4]$.



rounding mucosa, can be: elevated (0-IIa), at mucosal level (0-IIb) or depressed (0-IIc) [1].

The prefix "0" in the classification indicates a superficial lesion [1]. To differentiate between 0-Is and 0-IIb lesions, the use of closed biopsy forceps, which are $2.5 \mathrm{~mm}$ in diameter, is helpful. That is, if the change protrudes over the level of forceps and relies on the surrounding mucosa, the lesion is 0-Is [1]. 0-IIc type lesions have a depression of less than $1.2 \mathrm{~mm}$ (half the height of closed forceps), while 0-III lesions have a depression greater than $1.2 \mathrm{~mm}$ [1]. Values that are half of those mentioned are used for the oesophagus [1].

The significance of the Paris Classification in clinical application (Fig. 1) is that it allows for the depth of the invasion to be estimated. That is, flat type lesions (0-II), especially those with depression (0-IIc), as well as ulcerated lesions (0-III) are more often associated with submucosal invasion $[1,2]$. In the case of lesion type $0-\mathrm{I}$, the main predictor of invasiveness is the size of the lesion [1]. This classification also allows a combination of different classes to be incorporated into one finding, so as to obtain a more precise assessment of a particular lesion (e g., IIa + Is, IIa + IIc, III + IIc).

Although the depth of the invasion can be estimated endoscopically, the final decision on the therapeutic ap- proach is made on the basis of the histopathological examination of a biopsy sample obtained by endoscopic resection (ER) [2].

If protruded lesions have a lateral diameter $>10 \mathrm{~mm}$, without a significant increase in height, they are called laterally spreading tumours (LST) [1]. LST are classified into 2 types: non-granular (LST-NG) and granular (LSTG; Fig. 1). The LST-NG type is further divided into the flat elevated type (LST-NG-FE) and the pseudodepressed type (LST-NG-PD) [3, 4]. LST-G may be divided into homogeneous (LST-G-H) and nodular mixed (LST-G-NM) $[3,4]$. Granular, in particular, the LST-NG-PD subtype, are associated with a higher risk of advanced histology and submucosal invasion [3,5-7]. In a meta-analysis by Bogie et al. [3], the risk of submucosal invasion in LSTNG-PD, LST-G-NM, LST-NG-FE and LST-G-H was $31.6,10.5,4.9$ and $0.5 \%$ respectively.

\section{Chromoendoscopy}

Chromoendoscopy is used to improve the visualization of gastrointestinal lesions. There are 2 types of chromoendoscopy: dye (conventional) and virtual chromoendoscopy. Dye chromoendoscopy involves the use of Lu- 
gol's solution, acetic acid, indigo carmine, crystal violet and methylene blue.

Lugol's solution is used when detecting early squamous cell carcinoma (SCC). Specifically, normal oesophageal mucosa dyes with Lugol's solution, whereas the area with SCC does not take up colour.

The use of $1.5-3.0 \%$ acetic acid is used for the detection of dysplastic tissue. The dysplastic area shows an accelerated loss of aceto-whitening [8]. This colouring technique is used for the detection of dysplasia in Barrett's oesophagus (BE) $[1,9,10]$. Song et al. [11] concluded that the use of chromoendoscopy with acetic acid is a sensitive and specific method for estimating the intestinal metaplasia extension in the stomach, with sensitivity and specificity being 77.6 and $94.4 \%$ respectively.

Indigo carmine is used as a $0.1-0.4 \%$ solution and is employed to dye lesions that are suspect of being neoplasia [10].

Crystal violet as a $0.05 \%$ solution is used to dye lesions that are highly suspicious of invasive cancer [10].

Methylene blue is used as a $0.1 \%$ solution, absorbed by the epithelium, and enables better visualization of the mucosal pit, and is used to detect non-neoplastic or neoplastic lesions, which cannot be well visualized by classical endoscopy; this is used in cases with high suspicion of intestinal metaplasia, as well as in patients with ulcerative colitis $[1,10]$.

Despite the significance of chromoendoscopy, before the decision for any therapy is made, any suspicion of dysplasia must be confirmed with histopathological investigation [9].

\section{Advanced Endoscopy Techniques}

While standard endoscopy allows magnification up to 30 times, high-magnification endoscopy allows enlargement of the endoscopic image up to 100 times [10]. Highcontrast endoscopy, in addition to magnification, provides a detailed view of the mucosa, as well as visualization of microvasculature, which is important in the diagnosis of early lesions.

In addition to dye chromoendoscopy methods, virtual chromoendoscopy methods have been developed. These methods allow the use of chromoendoscopy without the use of dye. Since these techniques are based on the hardware and software characteristics of endoscopic systems, their activation is straightforward.

The oldest and most widely used method of virtual chromoendoscopy is narrow-band imaging (NBI), ini- tially developed by Olympus. The NBI principle is based on the elimination of red light from a standard red, green and blue spectrum. Because green and blue have a shorter wavelength than red (415, 540 and $650 \mathrm{~nm}$ respectively), their penetration into tissue is smaller, and once absorbed by haemoglobin from the blood vessels, better contrast visualization is produced [12]. When this technique is used, adenomas are seen as brown-coloured structures, contrasting from the surrounding green-coloured mucosa and dark-brown-coloured blood vessels [10].

Almost every manufacturer of endoscopic equipment has developed a virtual endoscopy system: Flexible spectral imaging colour enhancement (Fuji), I-Scan digital contrast (I-SCAN, Pentax) [12]. The principle is similar, however, except for NBI which has filters directly at the light source, all others produce a contrasting image after computer processing of the received data [12]. Autofluorescence imaging allows the differentiation between neoplastic and non-neoplastic tissue, and this mechanism is based on the autofluorescence of certain tissue structures when exposed to excitation by short wavelengths [12]. Confocal laser endoscopy provides virtual histology of tissue during endoscopy [13].

\section{Endoscopic Resection}

Biopsy obtained by ER is nevertheless regarded as the gold standard for determining the depth of invasion. Polypectomy, endoscopic mucosal resection (EMR), and endoscopic submucosal dissection (ESD) may be incorporated and considered ER. For early gastrointestinal lesions with or without limited submucosal infiltration, ER can serve diagnostic and therapeutic roles [9]. While EMR is unusable for lesions greater than $20 \mathrm{~mm}$, or nonlifting lesions, ESD can be applied for early lesions, regardless of their size [9].

Before performing ER, a good lesion assessment is required, using a high-resolution white-light endoscopy (HR-WLE) alongside chromoendoscopy [9].

The use of these techniques contributes to a clear categorization of lesions, in addition to providing assessment of the risk of submucosal invasion, both of which are necessary before a decision between EMR or ESD can be made [9]. Visualization of the glandular and vascular pattern is necessary, alongside an assessment of the size, localization and class of the lesion based on Paris Classification $[9,14,15]$. Patients with superficial lesions with submucosal invasion, which cannot be removed by EMR, are candidates for ESD [14]. 
In patients with neoplastic lesions localized deeper than the submucosa, or if the location of the lesion carries a high risk of perforation, a full-thickness resection can be performed [16]. This method removes all layers of the digestive tube lining infiltrated by the tumour, with closure of the defect with an over-the-scope clip. Resection $\mathrm{R} 0$ is achieved in $79 \%$ of cases, while clinical success is seen in $88 \%$ of instances [16].

\section{Oesophageal Superficial Lesions}

Oesophageal cancer is the eighth most common cancer and sixth most common according to mortality [17, 18]. In Asia, the most common histological type is SCC, while in Northern Europe and America adenocarcinoma predominates $[17,19]$.

Superficial carcinoma of the oesophagus is classified into the T1 group according to the TNM classification [17]. If the oesophageal carcinoma infiltrates the submucosa, it is classified as T2 class, which includes T2bsm 1, 2 or 3 , depending on which segment of the submucosa is infiltrated [17]. Intraepithelial carcinoma or lamina propria involvement has a negligible risk for nodal metastasis, whereas tumours involving the muscularis mucosa, superficial or deep submucosa and beyond have a metastatic frequency of $8-54 \%$ [19]. The highest risk for nodal metastases is seen in SCC [19].

Using classic endoscopy methods, early oesophageal carcinoma can be identified by the appearance of mucosal nodularity, lost vascular patterns, the appearance of subtle white coating, and erythema [19]. Superficial oesophageal neoplasia is most often detected as discrete flat lesions [17]. During endoscopy, special attention must be paid to the right lateral wall, and to the cervical narrowing of the oesophagus [19]. Due to frequent synchronous lesions, in patients with oesophageal SCC, visualization of the oropharynx and hypopharynx is necessary [19].

T2 lesions can often be endoscopically recognized as masses that protrude into the lumen with ulceration, and neovascularization, in conjunction to being areas void of peristalsis [17]. The assessment of superficial oesophageal lesions includes a description of localization, size, class according to Paris classification and the degree of circumferential involvement [17].

In addition to HR-WLE for detecting lesions, chromoendoscopy methods may be used. Using chromoendoscopy with Lugol's solution, the presence, extension, and depth of early oesophageal SCC can be determined [19]. There are 3 endoscopic signs: pink colour sign, tatami

Assessment of Early Gastrointestinal Lesions sign and leopard-skin appearance [19]. The use of advanced endoscopy techniques (primarily NBI) enables detection of early SCC, which is best visualized in the non-magnified mode as a brown area of mucosa [19]. In addition to early SCC, these altered fields are also seen in high- or low-grade dysplasia as well as in states of local inflammation [19]. The use of NBI is also important in analysing the microvasculature and intraepithelial papillary capillary loops, in addition to assessing the depth of lesions $[19,20]$.

Although chromoendoscopy may suggest a diagnosis, a definitive diagnosis is based, of course, on histopathological analysis of a biopsy or ER sample. For an adequate histopathological analysis, 2-3 samples from the lesion are usually obtained; however, one should remember that over-zealous sampling can cause submucosal fibrosis and impede subsequent ER [17].

Special attention should be paid to the presence of BE, which can lead to oesophageal adenocarcinoma. The risk of oesophageal adenocarcinoma in patients with $\mathrm{BE}$ is $0.3 \%$ per year $[21,22]$. Based on the recommendations of the European Society for Gastrointestinal Endoscopy (ESGE), surveillance in patients with BE is recommended using high-definition endoscopy, while the routine use of advanced endoscopy techniques is not recommended [21]. For adequate exploration, it is necessary to spend at least $1 \mathrm{~min}$ examining each centimetre of altered oesophageal mucosa $[23,24]$. In addition to the use of high-definition endoscopy and the routine use of the Prague classification, biopsies are necessary [25]. In the presence of BE, biopsies of 4 quadrants of the oesophagus with large-capacity forceps are recommended [21, $26]$. In the case of non-dysplastic BE, biopsies are performed at every $2 \mathrm{~cm}$, with low-grade dysplasia at 1-2 $\mathrm{cm}$, while in patients with high-grade dysplasia biopsies are taken at increments of $1 \mathrm{~cm}$ along the length of the area of BE $[21,26]$. In patients with an inflamed mucosal membrane with $\mathrm{BE}$, repeat endoscopy with biopsies after 2-3 months is advised in addition to acid-suppressive medical therapy [8]. Nevertheless, biopsies of every mucosal change seen on endoscopy (irregularity, elevation, depression, ulceration) should be taken, and sent for histopathological assessment.

ER is a curative modality for superficial neoplastic oesophageal lesions (T1), while oesophagectomy is reserved for patients with lesions stage T2 or higher, or those who are at high risk for nodal metastases [17]. Indeed, for superficial SCC with intraepithelial or lamina propria involvement, ER is considered the primary therapy [9]. Lesions classified as Paris 0-II are mostly intraepithelial, 
while lesions type 0-I and 0-III often infiltrate the submucosa, and are thus not suitable for ER $[9,19]$. The main criterion for selection between EMR and ESD is the size of the lesion, namely, lesions $<10 \mathrm{~mm}$ can be resected using EMR, while for larger lesions ESD therapy or surgery is recommended $[9,27]$. Based on ESGE recommendations, patients with visible macroscopic lesions with $\mathrm{BE}$ can be treated with ER [9]. The preferred method is EMR; however, if the changes are greater than 15 $\mathrm{mm}$, poorly lifting, or if there is a risk of submucosal invasion, ESD is recommended [9, 27]. Patients with BE and high-grade dysplasia or intramucosal carcinoma, without visible macroscopic changes, are treated with ablative techniques [9].

Unfortunately, most oesophageal carcinomas are detected once they are at an advanced stage, as stenosing or vegetative lesions with ulcers, where the treatment of choice has surpassed endoscopic modalities and is surgery or radiotherapy [17].

\section{Gastric Superficial Lesions}

Gastric cancer is the fourth most common cancer, second most common with regard to mortality [28]. The most common is adenocarcinoma (90\%), which can be of the diffuse or intestinal type [29]. If discovered at an early asymptomatic stage, 5-year survival exceeds 90\%, whereas in advanced cases, survival rates drop to approximately $16 \%$ [30].

For superficial gastric lesions, the following methods are used: HR-WLE, magnifying endoscopy (ME), and chromoendoscopy. Yu et al. [31], compared sensitivity and specificity of HD-WLE, ME and ME-NBI in the detection of early gastric cancer - sensitivity was $71.2,81.3$ and $87.2 \%$, respectively, and specificity was $99.1,98.8$ and $98.6 \%$ respectively [31]. The authors concluded that HDWLE has a relatively high precision for the diagnosis of early gastric cancer, and is an effective screening tool [31].

When using ME-NBI, the mucosa of the gastric corpus shows a regular arrangement of small, round pitches, surrounded by a subepithelial capillary network with a honeycomb appearance of collecting venula [32]. Antral mucosa shows the coil-shaped appearance of the subepithelial capillary network [32].

Changes in the pit pattern and regularity of microvasculature occur as a result of $H$. pylori infection, intestinal metaplasia and atrophic gastritis [32]. In intestinal metaplasia, a phenomenon known as "light blue crest sign" has been described [32].
Early gastric cancer, which involves only the mucosa, manifests endoscopically as a protrusion or depression with a smooth surface, mild marginal elevation and smooth convergence of the folds [9]. The appearance of irregular surfaces, significant marginal elevations, sudden discontinuity or convergence of congruent folds may indicate submucosal infiltration [9].

In patients with superficial gastric carcinoma, as previously mentioned, ER is the primary therapy, but only if the lesion has a very low risk of nodal metastasis [9]. ESD shows better control of resection margins, and is hence the preferred method, except in instances where lesions are less than 10-15 mm (Paris 0-IIa), where EMR is the ideal choice $[9,27]$.

\section{Case Report 1}

A 71-year-old patient was admitted to hospital to determine the cause of mild hypochromic anaemia. The patient had no subjective symptoms; however, a faecal occult blood test was positive. Colonoscopy indicated cecal angiodysplasia (Fig. 2). Argon plasma coagulation was performed. Upper endoscopy revealed the presence of a small angulus ulceration, and a rough surface of the antral region of the stomach (Fig. 2). Biopsies were taken (2 antral, 2 from the corpus, and 1 from the angulus). Prior to the completion of the histopathological report of stomach biopsies, and since chronic calculous cholecystitis was confirmed on ultrasound, a laparoscopic cholecystectomy was performed. Thus, the histopathological report of the stomach mucosa showed $H$. pylori negative multifocal atrophic gastritis, desquamative enteritis, intestinal metaplasia, alongside malignant cells in the angulus sample. Subtotal gastrectomy was thus indicated and performed. The intraoperative sample showed early diffuse type (G1) gastric carcinoma.

\section{Case Report 2}

A 69-year-old patient presented to the gastroenterology outpatient clinic due to dyspeptic symptoms lasting 2 years. He was previously tested for $H$. pylori, had received eradication therapy, and used proton pump inhibitors. He had never had an endoscopy. The upper endoscopy detected hyperemia and oedema of the antral mucosa, and numerous flat elevated lesions with central depressions (Paris 0-IIa + IIc) in the antral region (Fig. 3). Initial histopathological investigation pointed to multifocal atrophy, intestinal metaplasia, and tubular adenomas (dysplasia grade I-II). ESD was performed (Fig. 3). The definitive histopathological report described tubular adenomas with $30 \%$ high-grade dysplasia, and successful R0 resection margins. 

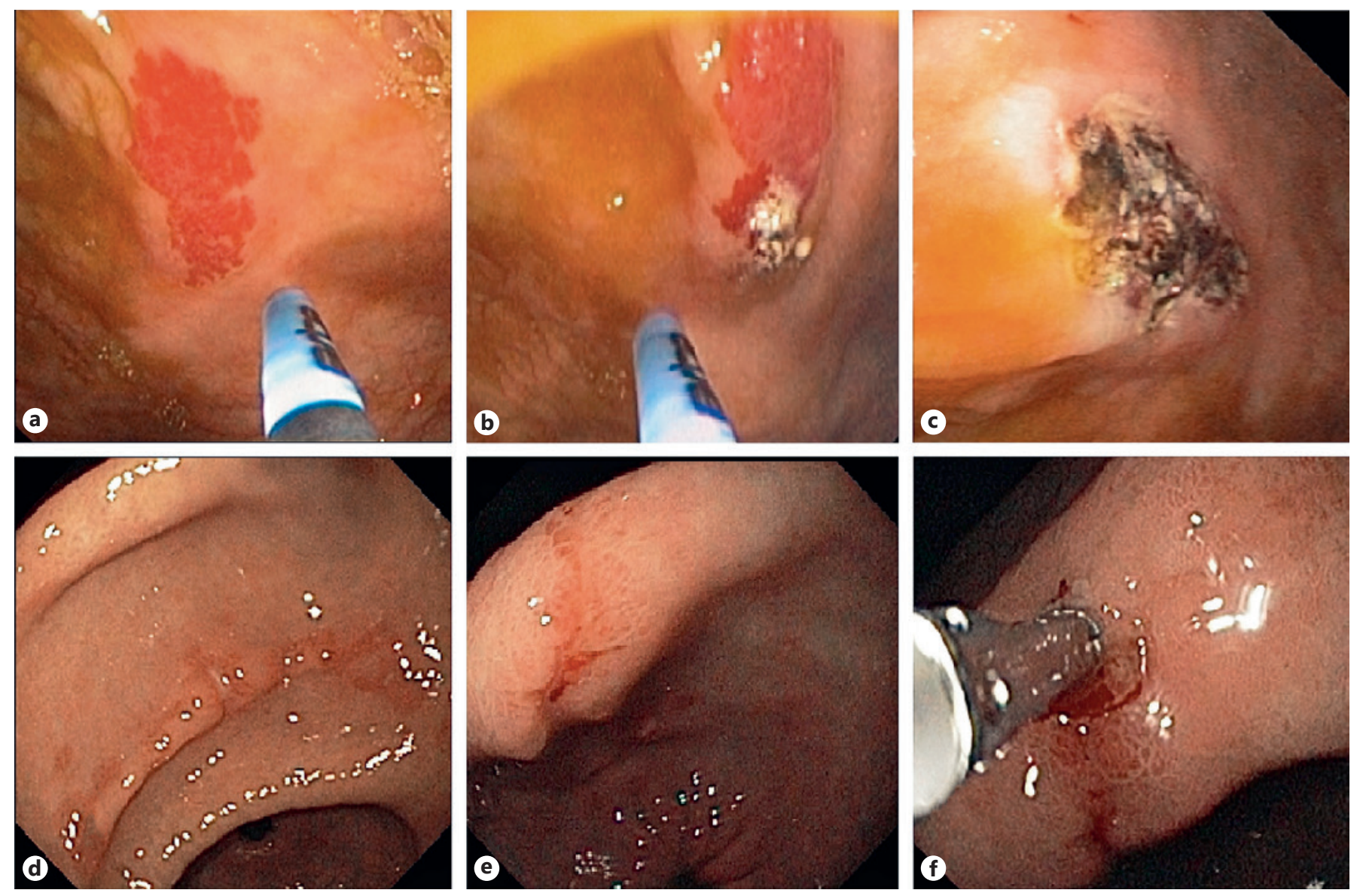

Fig. 2. a Cecal angiodysplasia, during (b), and after (c) argon plasma coagulation. Small angulus ulceration (d-f).

\section{Colorectal Superficial Lesions}

Colorectal carcinoma is the third most common cancer in men, and the fourth in women [28].

Using ME, a pit pattern can be analysed. Kudo et al. [33], defined 5 different types of pit patterns. Type I is characterized by round pits, type II-stellar or papillary pits, type IIIL-large tubular or roundish pits, type IIIS-small tubular or roundish pits, type IV branch-like or gyrus-like pits, with type $V$ characterized by non-structural pits. Pit pattern type I and II occur in normal or inflamed mucosa or in hyperplastic polyps, while other types occur in benign or malignant tumours [33]. More specifically, type I occurs in normal mucosa, type II in hyperplastic polyps, type IIIS and IIIL in adenomas, type IV in tubulovillous adenomas or intramucosal adenocarcinoma, and type $\mathrm{V}$ occurs in adenocarcinoma with infiltration of the submucosa [34].

The most frequently used classification for colon polyps is the Narrow band imaging International Colorectal
Endoscopic classification [35]. It involves assessing the colour, surface and vascular markings of the polyps.

Type 1 polyps are hyperplastic polyps, have a colour that is the same or brighter than the surrounding mucosa, a surface that may be dotted with dark or light spots that are uniform in size (or there is homogeneous absence of patterns), blood vessels may be absent or are present as isolated lacy vessels coursing across the lesion [12, 35]. Type 2 are adenomas, are darker brown in colour than the surrounding mucosa, with an oval surface, in conjunction to tubular or branched structures, surrounded by blood vessels [12, 35]. Type 3 polyps are considered invasive carcinoma, and are darker brown in colour than the surrounding mucosa, occasionally with patchy whiter areas, with an irregular surface and vascular patterns $[12,35]$.

Endoscopic removal of superficial lesions reduces the incidence and associated mortality rates from colorectal cancer [15]. Total colonoscopy, in addition to adequate preparation, cecal intubation and adequate time for with- 

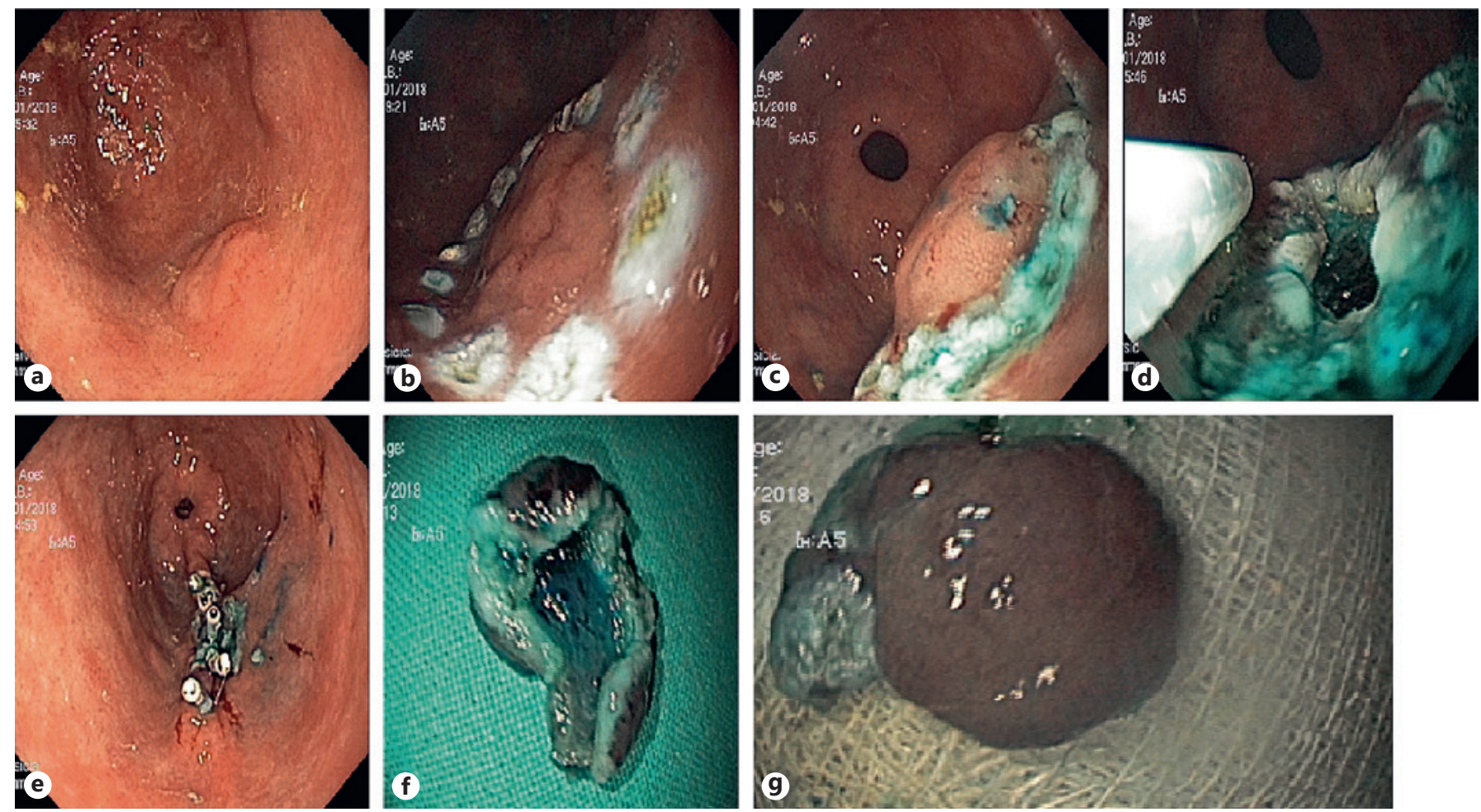

Fig. 3. a Flat elevated lesions with central depression in the antral region. b-e Endoscopic submucosal dissection.

f, $\mathbf{g}$ Sample after resection.

drawal of the endoscope, implies the removal of superficial lesions alongside biopsies of lesions that cannot be removed. A histopathological analysis of all resected polyps is recommended, except in the case of small diminutive polyps $\leq 5 \mathrm{~mm}$ in size, usually found in the rectal and/ or rectosigmoid region; here, the "resect and discard" approach is recommended [15].

The diagnostic and therapeutic approach to superficial colorectal lesions is based on ESGE recommendations [15]. Pedunculated polyps with a head size $<20 \mathrm{~mm}$ and a stalk $<10 \mathrm{~mm}$ are resected by hot snare polypectomy, as well as polyps with head size $\geq 20 \mathrm{~mm}$ and a stalk $\geq 10 \mathrm{~mm}$, where prior administration of adrenaline solution and/or prophylactic application of mechanical haemostasis reduces bleeding [15]. Superficial lesions, Paris Is or II class are treated depending on their size. If the size is $\leq 5 \mathrm{~mm}$, cold snare polypectomy is employed, or alternatively cold forceps polypectomy can be done if the diameter of the lesion is $\leq 3 \mathrm{~mm}$ [15]. If lesions are 6-9 $\mathrm{mm}$ in size, cold snare polypectomy are performed [15].

Lesions larger than $6 \mathrm{~mm}$ require the use of advanced endoscopy techniques, and identifying the presence of submucosal invasion is paramount [15]. If lesions are non-invasive, $10-19 \mathrm{~mm}$ in size, hot snare polypectomy with or without submucosal injection is applicable [10]. If the diameter of a lesion is $\geq 20 \mathrm{~mm}$, en block EMR is implemented, with the aim of achieving resection $\mathrm{R} 0$, or piecemeal EMR if the previous is not feasible or safe [15]. For lesions of size $>40 \mathrm{~mm}$, or invasive lesions, with suspected superficial submucosal infiltration, patients should be referred to an expert centre for en block EMR, ESD or surgery [15]. ESD is used for lesions with a depressed, irregular or NG surface morphology, and if they are larger than $20 \mathrm{~mm}$ [9]. Lesions susceptible to deep submucosal invasion should be referred for surgical treatment [15]. A tattoo of $3 \mathrm{~cm}$ distal from the lesion should be applied to $2-3$ places in all instances of suspected submucosal infiltration [15].

To properly assess LST lesions is of particular importance. That is, LST-G have a minimal risk for submucosal dissemination, and can be removed by ER, hence biopsies are not required [36]. In cases where lesions have a high risk of submucosal invasion, such as in LST-NG, 1-2 biopsies are recommended, especially where altered sites with depressions, elevations and/or ulcerations can be seen [36]. 


\section{Performance Measures for Endoscopy}

Based on ESGE recommendations, performance measures for upper endoscopy are carried out through the following domains: pre-procedures, completeness of procedure, identification of pathology, management of pathology, complications, number of procedures, patient experience and post-procedure [24]. The pre-procedure domain implies the percentage of patients who are referred to the procedure with proper instructions for fasting. Patients should fast for $6 \mathrm{~h}$ prior for solids, and $2 \mathrm{~h}$ for liquids [24].

The completeness of the procedure is estimated through the percentage of patients in whom the procedure was conducted for a duration of $\geq 7 \mathrm{~min}$, and in which key landmarks are documented through photography or video [24]. The target value for both variables is $\geq 90 \%$ [24].

The domain "identification of pathology" is measured through the proportion of patients in whom the lesions in the upper gastrointestinal tract are described using adequate terminology and standardized classification systems. In addition, a percentage of patients with adequate time for examination of the stomach, potential BE, and patients with chromoendoscopy with Lugol solution (who may be at risk of SCC) are assessed through this domain [24].

Management of pathology is assessed through the percentage of patients in whom the Seattle protocol is applied if they have BE, and in which the stomach is biopsied according to the "Management of precancerous conditions and lesions in the stomach" guidelines, if indicated [24]. The target value for this parameter is also $\geq 90 \%$ [24].

Assessment of the domain "complications" is based on the number of adequately described complications following interventional endoscopic procedures [24]. For the domains "number of procedures" and "patient experience," no defined standards currently exist [24].

The domain "post-procedure measures" assesses the percentage of patients in whom the recommended guidelines for monitoring and application of registers has been applied, if they have BE [24].

The performance measures for lower endoscopy are carried out through the following domains: pre-procedures, completeness of procedure, identification of pathology, management of pathology, complications, patient experience and post-procedure [37].

The pre-procedure domain includes the percentage of adequately prepared patients (target value $\geq 90 \%$ ), the time slot for colonoscopy and the presence of correct indications for colonoscopy [37]. The parameters for adequate pre-procedure are the following: Boston Bowel Preparation Scale $\geq 6$, the planned duration of the procedure ( $30 \mathrm{~min}$ for the routine colonoscopy and $45 \mathrm{~min}$ if the patient has a positive faecal occult blood test), while the indications for the colonoscopy are defined based on the appropriate guidelines [37-39]. The completeness of the colonoscopy is determined by cecal intubation, which should be done in $\geq 90 \%$ of cases [37].

The main parameter of the domain "pathology identification" is the adenoma detection rate (ADR), which should be $\geq 25 \%$, while the minor criteria are withdrawal time $(\geq 6 \mathrm{~min})$ and polyp detection rate (minimum $40 \%$ ) [37]. The key performance measurement parameter in lower endoscopy is ADR. It is inversely correlated with the risk of colorectal cancer interval [40]. The use of advanced endoscopy techniques, chromoendoscopy and devices attached to the endoscope can increase the ADR [41]. The results of the meta-analysis suggest that NBI may be better than standard white light colonoscopy; however, it is equal to high-definition white-light colonoscopy in the detection of colorectal adenomas or polyps [42]. Based on the data from the screening study, ADR in Serbia is $37.7 \%$ [43], while in Slovenia $51.3 \%$, with cecal intubation rates of $97.8 \%$ [43]. Screening data from Slovenia show that in $70.2 \%$ of patients colorectal cancer is diagnosed in the localized stage, while in $22.8 \%$, ER is the curative modality used [44].

"Management of pathology" involves the application of adequate technique ( $\geq 80 \%)$, the percentage of extracted polyps ( $\geq 90 \%)$, tattoo of the resection site, the use of advanced imaging techniques and the adequate description of polyp morphology [37]. The preferred classification for the description of colorectal lesions is the Paris Classification. In patients with lesions which show depression of the mucosa (Paris 0-IIc), or in patients with LST-NG or LST-G-NM, the use of advanced endoscopy techniques in the form of dye or virtual chromoendoscopy is recommended [37].

The complication domain implies the estimation of the percentage of patients with complications, in the form of the 7-day re-admission rate and 30-day mortality rate [37]. The domain patient experience, assesses the patient's experience during and after colonoscopy; while the post-procedure domain implies adherence to the appropriate post-polypectomy surveillance, which should be $\geq 95 \%$ [37]. 


\section{Ethics Statement}

The authors have no ethical conflicts to disclose.

\section{Disclosure Statement}

The authors declare that they have no conflicts of interest to disclose.

\section{Authors Contribution}

T.M.: made a significant contribution to the conception of the manuscript. T.M., D.P., M.K., and D.M.: conducted the research, analysed the data, wrote the draft and critically reviewed the manuscript. S.Z.: contributed to writing of the final draft, and critically reviewed the final manuscript.

\section{References}

1 The Paris endoscopic classification of superficial neoplastic lesions: esophagus, stomach, and colon: November 30 to December 1 , 2002. Gastrointest Endosc 2003;58(6 suppl): S3-S43.

2 Maes S, Haidry R, Bisschops R: Can the depth of invasion of early esophageal cancer be predicted based on endoscopic evidence? Minerva Chir 2018;73:385-393.

3 Bogie RMM, Veldman MHJ, Snijders LARS, Winkens B, Kaltenbach T, Masclee AAM, et al: Endoscopic subtypes of colorectal laterally spreading tumors (LSTs) and the risk of submucosal invasion: a meta-analysis. Endoscopy $2018 ; 50: 263-282$.

4 Kudo Se, Lambert R, Allen JI, Fujii H, Fujii T, Kashida H, et al: Nonpolypoid neoplastic lesions of the colorectal mucosa. Gastrointest Endosc 2008;68(4 suppl):S3-S47.

$5 \mathrm{Xu}$ MD, Wang XY, Li QL, Zhou PH, Zhang YQ, Zhong YS, et al: Colorectal lateral spreading tumor subtypes: clinicopathology and outcome of endoscopic submucosal dissection. Int J Colorectal Dis 2013;28:6372.

6 Uraoka T, Saito Y, Matsuda T, Ikehara H, Gotoda T, Saito D, et al: Endoscopic indications for endoscopic mucosal resection of laterally spreading tumours in the colorectum. Gut 2006;55:1592-1597.

7 Myung DS, Kweon SS, Lee J, Shin IS, Kim SW Seo GS, et al: Clinicopathological features of laterally spreading colorectal tumors and their association with advanced histology and invasiveness: an experience from Honam province of South Korea: a Honam association for the study of intestinal diseases (HASID). PLoS One 2017;12:e0184205.

8 Haidry RJ, Magee C: Mistakes in the endoscopic diagnosis and management of Barrett's oesophagus and how to avoid them. UEG Education 2018;2018:12-14.

9 Pimentel-Nunes P, Dinis-Ribeiro M, Ponchon T, Repici A, Vieth M, De Ceglie A, et al: Endoscopic submucosal dissection: European society of gastrointestinal endoscopy (ESGE) guideline. Endoscopy 2015;47:829-854.

10 Tanaka S, Kaltenbach T, Chayama K, Soetikno R: High-magnification colonoscopy (with videos). Gastrointest Endosc 2006;64:604613.
11 Song KH, Hwang JA, Kim SM, Ko HS, Kang MK, Ryu KH, et al: Acetic acid chromoendoscopy for determining the extent of gastric intestinal metaplasia. Gastrointest Endosc 2017; 85:349-356.

12 East JE, Vleugels JL, Roelandt P, Bhandari P, Bisschops R, Dekker E, et al: Advanced endoscopic imaging: European society of gastrointestinal endoscopy (ESGE) technology review. Endoscopy 2016;48:1029-1045.

13 Kiesslich R, Burg J, Vieth M, Gnaendiger J, Enders M, Delaney P, et al: Confocal laser endoscopy for diagnosing intraepithelial neoplasias and colorectal cancer in vivo. Gastroenterology 2004;127:706-713.

14 Auriemma F, Repici A: Mistakes in endoscopic resection and how to avoid them. UEG Education 2017;17:27-29.

15 Ferlitsch M, Moss A, Hassan C, Bhandari P, Dumonceau JM, Paspatis G, et al: Colorectal polypectomy and endoscopic mucosal resection (EMR): European society of gastrointestinal endoscopy (ESGE) clinical guideline. Endoscopy 2017;49:270-297.

16 Valli PV, Mertens J, Bauerfeind P: Safe and successful resection of difficult GI lesions using a novel single-step full-thickness resection device $\left(\right.$ FTRD $\left.^{\circledR}\right)$. Surg Endosc 2018;32:289299.

17 Barret M, Prat F: Diagnosis and treatment of superficial esophageal cancer. Ann Gastroenterol 2018;31:256-265.

18 Ferlay J, Soerjomataram I, Dikshit R, Eser S, Mathers C, Rebelo M, et al: Cancer incidence and mortality worldwide: sources, methods and major patterns in GLOBOCAN 2012. Int J Cancer 2015;136:E359-E386.

19 Shimamura Y, Ikeya T, Marcon N, Mosko JD: Endoscopic diagnosis and treatment of early esophageal squamous neoplasia. World J Gastrointest Endosc 2017;9:438-447.

20 Oyama T, Inoue H, Arima M, Momma K, Omori T, Ishihara R, et al: Prediction of the invasion depth of superficial squamous cell carcinoma based on microvessel morphology: magnifying endoscopic classification of the Japan esophageal society. Esophagus 2017;14:105-112.

21 Weusten B, Bisschops R, Coron E, Dinis-Ribeiro M, Dumonceau JM, Esteban JM, et al: Endoscopic management of Barrett's esophagus: European society of gastrointestinal en- doscopy (ESGE) position statement. Endoscopy 2017;49:191-198.

22 Desai TK, Krishnan K, Samala N, Singh J, Cluley J, Perla S, et al: The incidence of oesophageal adenocarcinoma in non-dysplastic Barrett's oesophagus: a meta-analysis. Gut 2012;61:970-976.

23 Gupta N, Gaddam S, Wani SB, Bansal A, Rastogi A, Sharma P: Longer inspection time is associated with increased detection of highgrade dysplasia and esophageal adenocarcinoma in Barrett's esophagus. Gastrointest Endosc 2012;76:531-588.

24 Bisschops R, Areia M, Coron E, Dobru D, Kaskas B, Kuvaev R, et al: Performance measures for upper gastrointestinal endoscopy: a European society of gastrointestinal endoscopy quality improvement initiative. United European Gastroenterol J 2016;4:629-656.

25 Sharma P, Dent J, Armstrong D, Bergman JJ, Gossner L, Hoshihara Y, et al: The development and validation of an endoscopic grading system for Barrett's esophagus: the Prague C \& M criteria. Gastroenterology 2006;131:1392-1399.

26 ASGE Standards of Practice Committee, Sharaf RN, Shergill AK, Odze RD, Krinsky ML, Fukami N, Jain R, et al: Endoscopic mucosal tissue sampling. Gastrointest Endosc 2013;78:216-224.

27 Lemmers A, Devière J: Mistakes in endoscopy and how to avoid them. UEG Education 2016: $16 ; 37-42$.

28 Jemal A, Center MM, DeSantis C, Ward EM: Global patterns of cancer incidence and mortality rates and trends. Cancer Epidemiol Biomarkers Prev 2010;19:1893-1907.

29 Karimi P, Islami F, Anandasabapathy S, Freedman ND, Kamangar F: Gastric cancer: descriptive epidemiology, risk factors, screening, and prevention. Cancer Epidemiol Biomarkers Prev 2014;23:700-713.

30 Isobe Y, Nashimoto A, Akazawa K, Oda I, Hayashi K, Miyashiro I, et al: Gastric cancer treatment in Japan: 2008 annual report of the JGCA nationwide registry. Gastric Cancer 2011:14:301-316.

31 Yu H, Yang AM, Lu XH, Zhou WX, Yao F, Fei GJ, et al: Magnifying narrow-band imaging endoscopy is superior in diagnosis of early gastric cancer. World J Gastroenterol 2015; 21:9156-9162. 
32 Boeriu A, Boeriu C, Drasovean S, Pascarenco O, Mocan S, Stoian M, et al: Narrow-band imaging with magnifying endoscopy for the evaluation of gastrointestinal lesions. World J Gastrointest Endosc 2015;7:110-120.

33 Kudo S, Tamura S, Nakajima T, Yamano H, Kusaka H, Watanabe H: Diagnosis of colorectal tumorous lesions by magnifying endoscopy. Gastrointest Endosc 1996;44:8-14.

34 Kudo S: Endoscopic mucosal resection of flat and depressed types of early colorectal cancer Endoscopy 1993;25:455-461.

35 Hayashi N, Tanaka S, Hewett DG, Kaltenbach TR, Sano Y, Ponchon T, et al: Endoscopic prediction of deep submucosal invasive carcinoma: validation of the narrow-band imaging international colorectal endoscopic (NICE) classification. Gastrointest Endosc 2013;78: 625-632.

36 Pita, Bastos, Dinis-Ribeiro: Mistakes in tissue acquisition during endoscopy and how to avoid them. UEG Education 2017;17:4547.

37 Kaminski MF, Thomas-Gibson S, Bugajski M, Bretthauer M, Rees CJ, Dekker E, et al: Performance measures for lower gastrointestinal endoscopy: a European society of gastrointestinal endoscopy (ESGE) quality improvement initiative. United European Gastroenterol J 2017;5:309-334.

38 Appropriate use of gastrointestinal endoscopy. American society for gastrointestinal endoscopy. Gastrointest Endosc 2000;52:831837.

39 Juillerat P, Peytremann-Bridevaux I, Vader JP, Arditi C, Schusselé Filliettaz S, Dubois RW, et al: Appropriateness of colonoscopy in Europe (EPAGE II). Presentation of methodology, general results, and analysis of complications. Endoscopy 2009;41:240-246.

40 Corley DA, Jensen CD, Marks AR, Zhao WK, Lee JK, Doubeni CA, et al: Adenoma detection rate and risk of colorectal cancer and death. N Engl J Med 2014;370:12981306.

41 Ngu WS, Rees C: Can technology increase adenoma detection rate? Therap Adv Gastroenterol 2018;11:1756283X17746311.

42 Nagorni A, Bjelakovic G, Petrovic B: Narrow band imaging versus conventional white light colonoscopy for the detection of colorectal polyps. Cochrane Database Syst Rev 2012;1: CD008361.

43 Banković Lazarević D, Krivokapić Z, Barišić G, Jovanović V, Ilić D, Veljković M: Organized colorectal cancer screening in Serbia the first round within 2013-2014. Vojnosanit Pregl 2016;73:360-367.

44 Tepeš B, Bracko M, Novak Mlakar D, Stefanovic M, Stabuc B, Frkovic Grazio S, et al: Results of the FIT-based national colorectal cancer screening program in Slovenia. J Clin Gastroenterol 2017;51:e52-e59. 